$\xi_{p}$

\title{
Theoretical and Experimental Analysis of Solar Still with Integrated Built-in Condenser
}

\author{
Ghaleb Ibrahim ${ }^{1}$, Husham M. Ahmed ${ }^{2}$ \\ 1. “American University of Dubai, AUD, College of Engineering, United Arab Emirates \\ 2, College of Engineering, AMA International University - Bahrain \\ *Corresponding author E-mail: gibrahim@aud.edu
}

\begin{abstract}
Water scarcity is one of the most important problems in Middle East and North Africa. Many researchers believe that solar distillation is the best solution to solve water scarcity, especially since these areas are characterized by abundant solar energy most days of the year. One of the main disadvantages of solar distillates is the low rate of production and therefore the research focuses on the factors that many enhance and improve the rates of production of the solar stills.

In this paper, the performance of a passive built in condenser incorporated into a solar still is studied theoretically and experimentally using. A theoretical framework is developed to forecast the productivity performance (accumulated and hourly), the temperatures of the various elements of the stills. The theoretical and experimental results were compared together and discussed thoroughly. Both theoretical and experimental results were in good agreement. The behaviors of both agree well with each other and have similar trends.

Keywords: Solar stills Mathematical modeling; Water desalination; passive Built-in Condenser
\end{abstract}

\section{Introduction}

One of the essentials for sustainable development is the provision of freshwater for human activity. Day after day, access to fresh water is shrinking worldwide, especially in the Middle East and North Africa. Groundwater is heavily over used. The situation is propagating due to land degradation and aridity. All expectations indicate that the problem will worsen as the days pass. The positive point is that most of the regions that are severely under-resourced have a huge supply of solar energy. Many researchers believe that solar energy is highly promising renewable energy compared to fuel. [1-4].

Solar stills (used to produce distilled water) are one of the main options offering sustainable tool for producing freshwater from solar energy. In addition to being a simple technique, it is economically efficient, and environmentally friendly. Simple Conventional solar stills have been used in the past few decades on a large scale. The main deficiency is that they have low outputs compared to other thermal or membrane systems. This low productivity lead researchers to focus on the study of the various factors that promote and enhance productivity rate through the adoption of different techniques and the exploration and application of different designs to improve the level of the solar still productivity. Different methods are used such as to integrate different design of condensers into the traditional solar still [5-6]. A wide review on external and internal condenser incorporated into solar stills is published by Kabeel et al. [[7]. the review pointed out that solar stills with incorporated condensers had a positive effect in increasing the rate of productivity. many researches were done on the solar still incorporating condenser [8-12]. Madhlopa [8] and
Madhlopa and Johnstone [9] showed that the use of an external or internal condenser increases the productivity rate by up to $62 \%$ when compared to the solar still excluded the condensers. In addition the enhancement of productivity due to their use of condenser was found to be $40 \%$ of the total distillation output. Ahmed [10] reported that the enhancement of the condenser-type solar still performance differs greatly for different techniques due to different experimental conditions. Fath and Hosny [11] presented a theoretical study of the thermal performance of a single-sloped basin still with enhanced evaporation and a built-in additional condenser and found to produce a yield of about 55\% over the base case. Khalifa et al. [12] used an internal condenser in their work to enhance the distillate water productivity using internal condenser. They also performed comparable to water quality standards, against rain water and mineral water. Their experiment delivered in terms of the daily efficiency of about $54 \%$.

The current work is an extended analysis to the experimental study of a built-in passive condenser incorporated into a solar still and to the mathematical model has been carried out and presented in ref. $[13,14]$.

\section{Design and Construction of Solar Still}

A complete system of a single slope solar still with a passive built in condenser has been designed and constructed. The system was tested under the climate of Salmabad $\left(26.19^{\circ} \mathrm{N}, 55.53^{\circ}\right.$ E) Kingdom of Bahrain. The system comprises from two connected chambers, the single slope conventional solar still chamber and the built-in 
condenser chamber. The schematic diagram of the setup is shown in fig 1. The body of the two chambers was made from $1.4 \mathrm{~mm}$ thick galvanized steel. The front sloped side of the conventional chamber, inclined to latitude of $20^{\circ}$ was covered with glass sheet of $4 \mathrm{~mm}$ thick. The cover of the slanted back chamber was made from galvanized steel and represented the condenser wall at which water condenses. The horizontal area of the net basin of the conventional solar still chamber is $\left(1 \times 1=1 \mathrm{~m}^{2}\right)$. The basin and side walls of the still were painted black to maximize the absorptivity of the solar radiations. Furthermore and in order to minimize heat losses, the bottom and all side walls of galvanized steel were very well insulated with $50 \mathrm{~mm}$ glass wool. This is being supported by another $50 \mathrm{~mm}$ thick wooden board in form of farm box. To prevent any possible vapor leakage, the glass cover was well and tightly sealed using Thermal silicon paste. To ensure that the galvanized surface temperature is not affected by direct sun rays, a polystyrene board has been placed at the top of the back side of solar still.

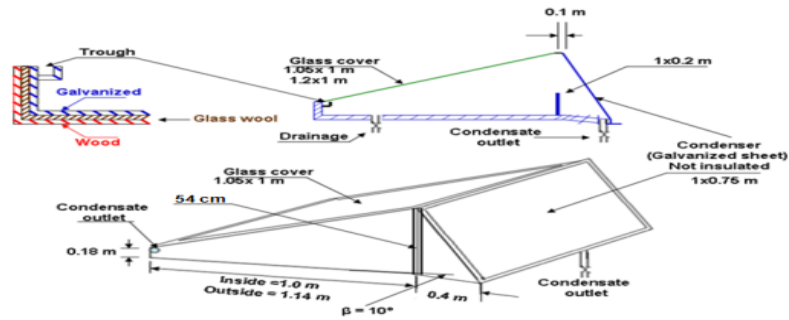

Fig. 1 Schematic diagram of the solar still with dimesion

An inlet pipe was provided to feed the saline water to the basin of the solar still. A $40 \mathrm{~mm}$ x $40 \mathrm{~mm} \mathrm{~L}$ shaped trough was manufactured from galvanized steel and placed at the inside of the front edge of the conventional solar still. It was used to collect the condensate water running down the inclined glass cover sheet. The trough was fixed with a slight slope to facilitate smooth flow of the condensate water into the plastic graduated flask.

Six thermometers and ten thermocouples were used to measure temperature at different eight different locations. For the purpose redundancy and of verifying the accuracy of reading, two thermometers / thermocouples have been installed to measure each temperature parameter at each location. These locations were the inner and outer sides of the glass cover, the inner and outer sides of galvanized cover of the built-in condenser, galvanized basin of the solar still, saline water temperature, water vapor (space) temperature under the glass cover (conventional solar still chamber) and under the galvanized cover (the built-in condenser chamber), and the ambient temperature. All thermocouples were connected to digital temperature indicators.

To ensure the measurement accuracy of the Thermometers and the thermocouples, care was taken to place and fix them in places that no direct sun rays can reach them directly. The intensity of solar radiation on the surface of the inclined glass cover was measured using a Daystar type solar meter. A digital wind anemometer was used to measure the wind speed at the solar still height.

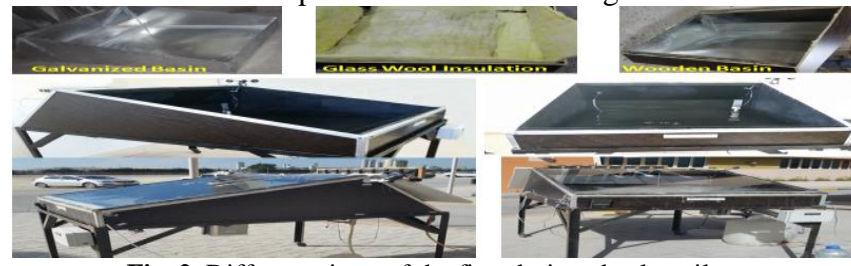

Fig. 2 Different views of the first designed solar stil

\section{Principles of Solar Still With Built-in Condenser}

The work of the solar still is a simulation of the heat and mass transfer principles. It is a modelling representation of the greenhouse effect where solar radiation is used to evaporate the water at the bottom of the solar still. When solar radiation strikes the glass cover, a small part of the incident solar radiation is reflected from the surface while the glass cover absorbs another small portion of the radiation. The amount absorbed depends on the glass material quality and impurity and the thickness of the solar still cover. Most of the incident solar radiation penetrates and passes through the glass cover into the water at the bottom of the solar basin. The water absorbs most of solar radiation while the rest is transmitted to the basin made of galvanized steel and coated with black paint to increase absorption rate. When the water absorbs the radiation and the temperature raise, then the process of evaporation from the water surface increases steadily. The spaces inside the solar still become saturated and its temperature becomes higher than the glass cover inner side. When the temperature of the glass cover inner side reaches the dew point in respect to the vapor temperature, the vapour will begin to condense. The condensate will accumulate and run down the inclined surface of the glass cover. The inside surface of the glass cover cools down as it transfers heat through material to the outer surface and consequently to the atmosphere. Therefore ambient temperature play an important role in the amount of vapor condensed. The sun radiations absorbed by water is the source of energy for evaporation and it consequently its intensity is main factor controlling the performance and productivity of the system. Adding a built-in condenser will give another possible surface area for the accumulated saturated vapour inside the solar still to condense. The evaporated water must be compensated to keep the water level in the tank steady [15-17].

\section{Experimental Pproceduer}

Undoubtedly, solar radiation and thus its intensity is the main parameters affecting the performance of a solar still system. Therefore, each set of experiments were conducted along two clear sky days. In addition, and to ensure stability of the solar still preliminary tests were conducted under real climatic conditions. . All tests started at 7:00 am and carried out till 5:00 pm local time. Measurements of all parameters were recorded on one hour interval. Furthermore, at the beginning of each experimental test, the saline water level in solar still basin tank was fixed at $1 \mathrm{~cm}$ height. A make up supply were provided during the test equivalent to amount condensed and collected

\section{Mathematical Model}

The analysis of the current system was developed using some basic experimental data such as the measured solar, wind speed, and ambient temperature. The energy and mass balance of the solar still are derived from the principles of heat and mass transfer with the required mathematical formulation within and around the system. Fig. 3 shows the thermal energy mechanisms in the still.

The mathematical relations describing the heat and mass transfer occurring in the components of the solar still (such as the still cover, brackish water, basin and the condenser) are given as follows: 


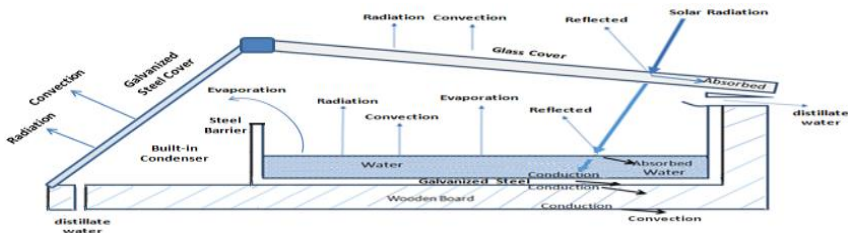

Fig. 3 Thermal energy transfer modes

\subsection{Glass cover}

The thermal balance of the cover is time dependent due to the change in surrounding and ambient conditions during the operation of the system. Thus, the energy stored by the glass must be equal to the energy entering the still through the glass minus that leaving; the energy entering, is the solar intensity, the heat transfer due to convection, radiation and evaporation between within the solar still. The energy leaving is the summation of energy lost due to radiation, reflection and convection between glass and the surrounding and ambient.

$$
\begin{aligned}
& I(t) A_{g} a_{g}+Q_{c, w-g}+Q_{r, w-g}+Q_{e, w-g}=m_{g} C p_{g}\left(\frac{d T_{g}}{d t}\right)+ \\
& Q_{r, g-s k y}+Q_{c, g-a}
\end{aligned}
$$

\subsection{Galvanized steel condenser}

Similar thermal energy balance may be applied to the galvanized steel with exception that no direct solar radiation reaches the steel surface. Therefore, the energy stored by the steel must be equal to the total energy gained (due to convection, radiation and evaporation from water to condenser surface) and that lost by radiation and convection between outside condenser surface and its surrounding and ambient conditions, plus the stored energy by condenser.

$$
Q_{c, w-c}+Q_{r, w-c}+Q_{e, w-c}=m_{c} C p_{c}\left(\frac{d T_{g}}{d t}\right)+Q_{r, c-s k y}+Q_{c, c-a}
$$

Saline water; it gains energy from the solar radiation transmitted through glass and the solar still base. This energy is balanced by the energy stored plus that lost by:

1- Convection, radiation and evaporation process, plus

2- the energy of the compensated evaporated water by colder water,

3- the thermal losses through side wall loss and

4- assuming negligible water reflectance

$$
\begin{aligned}
& Q_{c w}=Q_{c w g}+Q_{c w s} ; Q_{r w}=Q_{r w g}+Q_{r w c} ; Q_{e w}=Q_{e w g}+ \\
& Q_{e w c}
\end{aligned}
$$

$I(t) A_{w} a_{w}+Q_{c, b w}=m_{w} C p_{w}\left(\frac{d T_{w}}{d t}\right)+Q_{c, w g / c}+Q_{r, w}+Q_{e, w}+$

$Q_{f w}+Q_{s w, l o s s}$

The basin thermal balance; the basin receives solar radiation transmitted through water. This energy is balanced by the energy stored in the basin, plus;

5- the connection between basin and water,

6- loss of heat from outer surface of the basin

7- assuming negligible zero reflectance

$I(t) A_{b} a_{b}=m_{b} C p_{b}\left(\frac{d T_{b}}{d t}\right)+Q_{c, b w}+Q_{b, \text { loss }}$

Where; $a_{g}=\alpha_{g}\left(1-r_{g}\right) ; a_{w}=\alpha_{w} \tau_{g}\left(1-r_{g}\right)$;

$$
\begin{aligned}
& a_{b}=\alpha_{b} \tau_{g} \tau_{w}\left(1-r_{g}\right) \\
& T_{w}=T_{w}+d T_{w} \\
& T_{g}=T_{g}+d T_{g} \\
& T_{c}=T_{c}+d T_{b} \\
& T_{b}=T_{b}+d T_{b} \\
& \frac{d m_{c}}{d t}=\frac{h_{e, w g}\left(T_{w}-T_{g}\right)}{h_{f g}} \\
& Q_{c, b w}=h_{c, b w} A_{b}\left(T_{b}-T_{w}\right) \\
& Q_{b, l o s s}=U_{b} A_{b}\left(T_{b}-T_{a}\right) \\
& Q_{f w}=\dot{m}_{e} c_{w}\left(T_{w}-T a\right) \\
& Q_{s w, l o s s}=U_{s w} A_{s w}\left(T_{w}-T_{a}\right) \\
& Q_{c, w g(c)}=h_{c, w g(c)} A_{g(c)}\left(T_{w}-T_{g(c)}\right) \\
& h_{c, w g(c)}=0.884\left\{\left(T_{w}-T_{g(c)}\right)+\frac{\left(P_{w}-P_{g(c)}\right)\left(T_{w}+273.15\right)}{\left(286.9 \times 10^{3}-P_{w}\right)}\right\}^{1 / 3}
\end{aligned}
$$

The radiation heat transfers (water - glass) is

$Q_{r, w g(c)}=h_{r, w g} A_{g(c)}\left(T_{w}-T_{g(c)}\right)$

$h_{r, w g(c)}=\varepsilon \sigma\left[\left(T_{w}+273.15\right)^{2}+\left(T_{g(c)}+273.15\right)^{2}\right]\left(T_{w}+T_{g(c)}+\right.$ 546)

Where $h_{r, w g(c)}$ and $h_{c, w g(c)}$ are the radiation and convection heat transfer coefficients respectively (water-glass)

Where $\varepsilon_{e q}=\frac{1}{\left(\frac{1}{\varepsilon_{w}}+\frac{1}{\varepsilon_{g}}-1\right)}$

The evaporation process (water-glass) is

$Q_{e, w g(c)}=h_{e, w g(c)} A_{g(c)}\left(T_{w}-T_{g(C)}\right)$

Where the evaporation heat transfer coefficient of (water-glass) is

$h_{e, w g(c)}=\left(16.273 \times 10^{-3}\right) h_{c, w g}\left(P_{w}-P_{g(c)}\right) /\left(T_{w}-T_{g(c)}\right)$

The radiation heat transfers (sky-glass) is

$Q_{r, g(c)-s k y}=h_{r, g-s k y} A_{g(c)}\left(T_{g(c)}-T_{s k y}\right)$

The radiation heat transfer coefficient (glass-sky) is

$h_{r, g(c)-s k y}=\varepsilon \sigma\left[\left(T_{w}+273.15\right)^{4}+\left(T_{g(c)}+273.15\right)^{4}\right]\left(T_{g(c)}+\right.$
$\left.T_{s k y}\right)$

The effective sky temperature is

$T_{s k y}=T_{a}-6$

The convection heat transfers (glass-sky) is

$Q_{c, g(c)-a}=h_{c, g(c)-s k y} A_{g(c)}\left(T_{g(c)}-T_{a}\right)$ 
Where $h_{c, g(c)-a}$ is depending solely on the wind velocity as

$h_{c, g(c)-a}=2.8+3.0 \mathrm{~V}$

$C$. the overall heat transfer coefficients of basin and side wall The temperatures of the inside components of the solar still (basin, water and air) are than the outside ambient temperature. Thermal energy will be lost to outside surrounding. To reduce the heat loss, the bottom and side walls are insulated. It is required to apply the insulation properly so that thermal resistance will be the dominant one in the heat transfer through basin and the walls. However in the analysis all thermal resistances may be taken into consideration to give the overall heat transfer coefficient of basin as:

$U_{b}=1 /\left(\frac{1}{h_{a}}+\frac{x_{p w}}{k_{p w}}+\frac{x_{i n}}{k_{i n}}+\frac{x_{s}}{k_{s}}\right)$

Where the insulation thermal resistance $\left(\frac{x_{i n}}{k_{i n}}\right)$ is dominant.

The side wall heat transfer coefficient $U_{s w}$, is given by refs. $[5,8$, and 9] as:

$U_{s w}=U_{b} \frac{A_{s w}}{A_{b}}$

$U_{s w}$ was reported in the literature in the magnitude of $20 \mathrm{~W} / \mathrm{m}^{2} \mathrm{~K}$ [8] and $0.5 \mathrm{~W} / \mathrm{m}^{2} K$ [9]. Hitesh [18] used $U_{s w}$ of $20 \mathrm{~W} / \mathrm{m}^{2} K$. In this present study the heat lost through the side wall is obtained as

$U_{s w}=1 /\left(\frac{1}{h_{a}}+\frac{x_{p w}}{k_{p w}}+\frac{x_{i n}}{k_{i n}}+\frac{x_{s}}{k_{s}}+\frac{1}{h_{c w}+h_{r w}}\right)$

The condenser area to glass cover area ratio

$A c g=A c / A g$

Where $h_{c w}=h_{c, w g}$ and $h_{r w}=h_{r, w g}$. These coefficients vary with time and must be determined at each time step.

\section{Results and Discussion}

In the current study, a theoretical investigation of the performance and productivity of the condenser incorporated into solar still has been conducted.

The set of mathematical equations were solved using the Euler method. The model was validated by previously experimentally obtained results by Ahmed et al [13]. Therefore this mathematical model was solved under same conditions of the experimental study. Thus the external parameters (solar intensity, ambient temperatures and wind speed) were measured and used in the model. Table 1 shows the various properties used in this model. All measurable external parameters must be known in advance to solve the theoretical model. In the current study these parameters were taken from previous experimental work [13].

To compare between the model and the experiment, the results were presented graphically in Fig. $4-$ Fig. 7. The obtained results are the hourly and accumulated rate productions, and temperatures of the still components were calculated. It is of great importance to illustrate the magnitude of heat transfer through the still cover and the condenser to the outside environment. This is shown in Fig. 8. The results presented in the figure are obtained from the mathematical model. In addition the ratio of rate of heat transfer across still cover to that through the condenser is shown in Fig. 8. From Fig. 8 it can be seen clearly that the ratio at early morning is relatively high indicating that more thermal energy is transferred through the glass cover. This ratio drops when time passes and reaches minimum at close to 2:00 p.m. On the other hand the maximum rate of heat transfer across the still cover and condenser occurs earlier at 1:00 p.m.

The difference in the magnitude of heat transfer between still cover and condenser may be due to the low emissivity of condenser material in comparison to the glass. This low emissivity reduces the radiation heat transfer coefficient of the condenser.

Although there is some discrepancies between theory and experiment, both shows the similar behavior and so the results relatively close. The discrepancies between theoretical and experimental are tabulated in Table 2.

On average basis, comparison of the accumulated production rate between theory and experiment shows that they discrepancy in the magnitude of; $19 \%, 33.4 \%$ and rate $4.7 \%$ for glass cover, the condenser and total accumulated production rate respectively. Also on average basis the temperatures of brackish water, basin, cover and condenser obtained from the theory with respect to those obtained from the experiment. The discrepancies found to be $3.44 \%$ for brackish water, $7.7 \%$ for basin, $8.33 \%$ for still cover and $5.4 \%$ for condenser see Table 2 . The production rates from the theory in comparison to experimental results, it shows that the theoretical model produces approximately $1.589 \mathrm{~L} /$ day where under the same condition the experiment produces $1.54 \mathrm{~L}$ per day. The daily productivity over the glass cover were from the theoretical model 0.991 liters whereas from the experiment 1.11 liters and over the condenser from the model cover 0.595 liters whereas from the experiment 0.614 liters.

Fig. 9 shows that the effect of the ratio of area of condenser to area of glass on the end of day production rate. From the figure the followings can be deduced; 1) the slope of the total production decreases with increasing the area ratio. This will have an impact on the how large the condenser area should be for a feasible design of a solar still with a Built-in Condenser. 2) the production rate of the glass cover drops with increasing the area ratio. 3) the condenser rate of production partially compensates the drop in production rate by the glass and partially enhances the total production such that production rate $(\mathrm{c})=$ production rate drop by glass cover $(\mathrm{b})+$ production rate enhancement (a).

Table 3 also shows that there is a theoretical maximum condenser to glass areas ratio at which the total production starts decreasing. The maximum occurs approximately at Asg $=11.425$. This maximum is obtained under the current measured external parameters. However, designing a solar still with Built-in Condenser, the practical Asg may be way below that maximum due to other constrains such as economics, practicality and portability.

\section{Table 1 applied parameters}

\begin{tabular}{|l|c|c|c|c|c|}
\hline Parameter & Symbol & water & Basin & $\begin{array}{l}\text { Glass } \\
\text { cover }\end{array}$ & $\begin{array}{l}\text { Galvanized } \\
\text { steel condenser }\end{array}$ \\
\hline Absorptivity & $\alpha$ & 0.05 & 0.90 & 0.05 & - \\
\hline Transmissivity & $\tau$ & 0.95 & - & 0.9 & - \\
\hline Emissivity & $\epsilon$ & 0.96 & - & 0.98 & 0.28 \\
\hline Reflectance & $\phi$ & 0.05 & - & 0.13 & - \\
\hline Specific heat & $c_{p}(J / \mathrm{kg} \mathrm{K})$ & 4187 & 490 & 670 & 510 \\
\hline
\end{tabular}

Table 2 discrepancy between theory and the experiment

\begin{tabular}{|l|c|c|c|c|}
\hline & $\%$ & $\begin{array}{c}\text { Glass cover } \\
\%\end{array}$ & $\begin{array}{c}\text { Condenser } \\
\%\end{array}$ & Total \\
\hline Saline water temperature & 3.5 & & & \\
\hline Basin temperature & 7.7 & & & \\
\hline Glass temperature & 8.56 & & & \\
\hline Condenser & 5.3 & & & \\
\hline Productivity & & 19 & 33.4 & 4.7 \\
\hline
\end{tabular}


Table 3 the end of day accumulated production

\begin{tabular}{|c|c|c|c|}
\hline & \multicolumn{3}{|l|}{ End of day accumulated production } \\
\hline & Glass & Condenser & Total \\
\hline 0 & 1430.969 & 0 & 1430.969 \\
\hline 0.4 & 1146.728 & 382.1381 & 1528.866 \\
\hline 0.8 & 961.2818 & 637.4301 & 1598.712 \\
\hline 1 & 889.7199 & 736.07 & 1625.79 \\
\hline 8 & 270.6598 & 1562.023 & 1832.683 \\
\hline 10 & 232.3002 & 1604.864 & 1837.164 \\
\hline 11 & 217.7599 & 1620.055 & 1837.814 \\
\hline 11.4 & 212.5802 & 1625.289 & 1837.8693 \\
\hline 11.425 & 212.2672 & 1625.602 & 1837.8693 \\
\hline 11.5 & 211.3355 & 1626.532 & 1837.8671 \\
\hline 12 & 205.3909 & 1632.38 & 1837.7704 \\
\hline
\end{tabular}

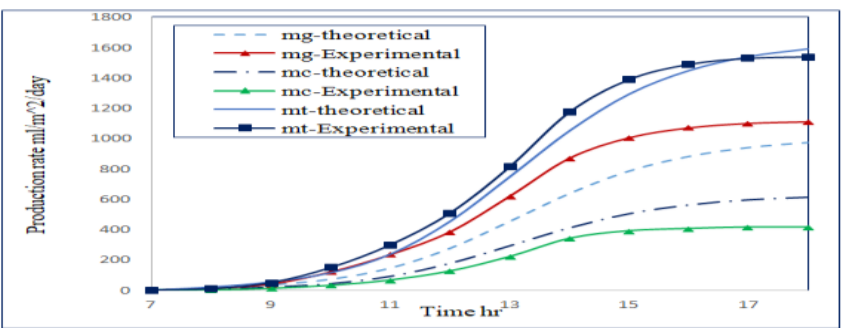

Fig. 4 accumulated production rate; a comparison bteween the theory and the experiment

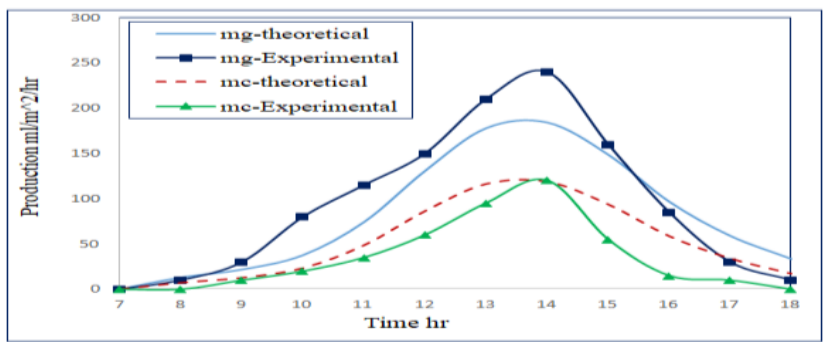

Fig.5 hourly production rate; a comparison bteween the theory and the experiment

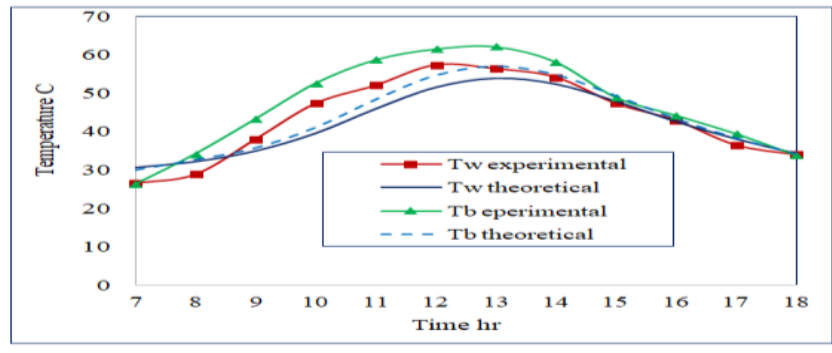

Fig. 6 brackish water and basin temperatures

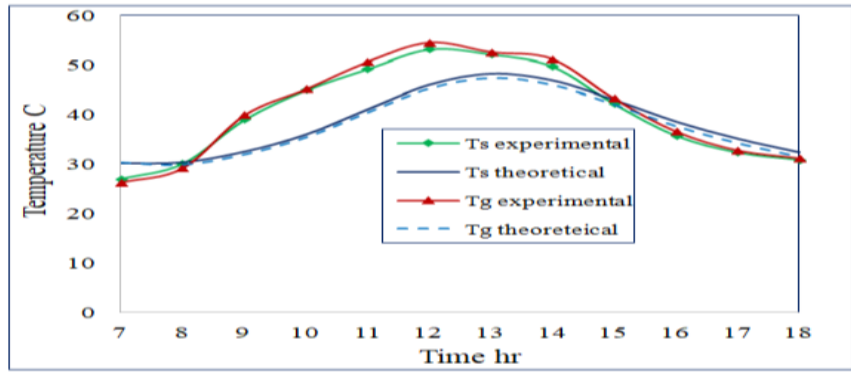

Fig. 7 Glass cover and condenser temperatures;

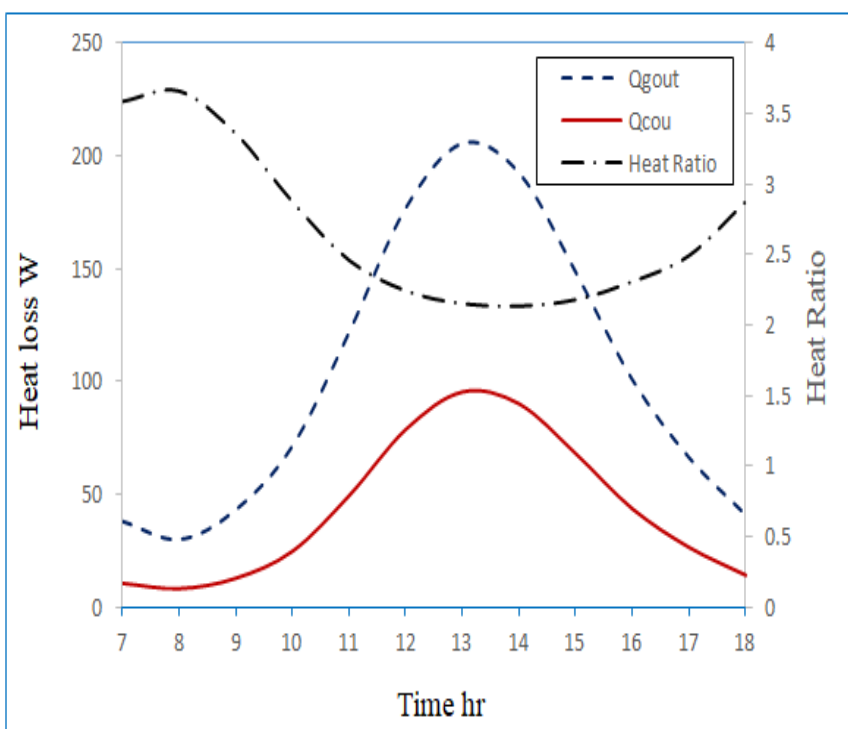

Fig. 8 Theoretical heat transfer rate of the glass cover and the galvanized steel condenser.

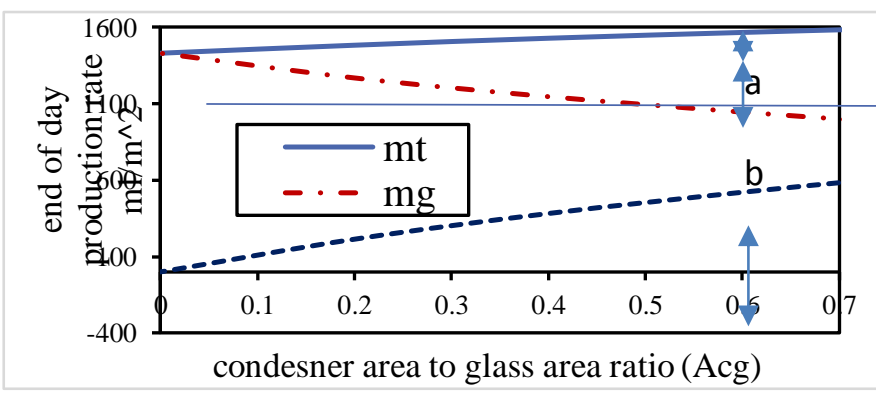

Fig.9 Effect of area ratio (Acg) on the end of day production rate

\section{Conclusions}

The predicted production rate from the theoretical model is compared to that obtained from the experiment, where the agreement between them is within the acceptable range. The trends of both are also in good agreement. The enhancement of the theoretically predicted values from the glass cover follows those obtained form of the experiment. But at around three O'clock afternoon the theoretical improvement began to increase over that of the experiment. This might be referred to the fact that the still cover temperature obtained experimentally drops below the model at around 3 p.m. On the other hand, it should be noted that the larger the ratio of the condenser area to glass cover area, the larger the drop in the production rate of glass cover. This drop is compensated by the production rate of the condenser. The condenser production is partially to compensate the drop by the glass and partially to enhance the production. Also the total production of both the glass and condenser has a maximum that theoretically occurs at approximately Ags $=11.425$

\section{Nomenclatures}

$\begin{array}{ll}\text { “A } & \text { area, }\left(\mathrm{m}^{2}\right) \\ \mathrm{a} & \text { solar radiation factor } \\ C & \text { specific heat, }(\mathrm{J} / \mathrm{kg} \mathrm{K}) \\ h & \text { heat transfer coefficient, }\left(\mathrm{W} / \mathrm{m}^{2} \mathrm{~K}\right) \\ \mathrm{h}_{\mathrm{fg}} & \text { enthalpy of evaporation at } \mathrm{Tw},(\mathrm{J} / \mathrm{kg}) \\ \mathrm{I}(\mathrm{t}) & \text { intensity of solar radiation, }\left(\mathrm{W} / \mathrm{m}^{2}\right)\end{array}$




$\begin{array}{ll}\mathrm{m} & \text { mass, }(\mathrm{kg}) \\ \mathrm{P} & \text { partial pressure, }(\mathrm{Pa}) \\ \mathrm{r} & \text { reflectance } \\ \mathrm{T} & \text { temperature, }{ }^{\circ} \mathrm{C} \\ \mathrm{U} & \text { heat transfer coefficient, }\left(\mathrm{W} / \mathrm{m}^{2} \mathrm{~K}\right) \\ \mathrm{V} & \text { wind velocity, }(\mathrm{m} / \mathrm{s}) \\ \mathrm{t} & \text { time } \\ \mathrm{X} & \text { thickness }(\mathrm{m}) \\ & \\ \text { Greeks } & \\ \alpha & \text { absorptivity } \\ \varepsilon & \text { emissivity } \\ \rho & \text { density, }\left(\mathrm{kg} / \mathrm{m}^{3}\right) \\ \tau & \text { transmissvity }\end{array}$

$\begin{array}{ll}\text { Subscripts } & \\ \text { a } & \text { ambient } \\ \text { b } & \text { basin } \\ \text { bw } & \text { basin-water } \\ \text { c } & \text { convective, condenser } \\ \text { e } & \text { evaporation } \\ \text { eq } & \text { equivalent } \\ \text { fw } & \text { feed water } \\ \text { g } & \text { glass } \\ \text { g(c) } & \text { either glass or condenser used to distinguish the equation } \\ & \text { above } \\ \text { g-sky } & \text { glass-sky }\end{array}$

[5] "Shadi, M., Abujazar, S., Fatihah, S., Rakmi, A. R., Shahrom, M. Z. The effects of design parameters on productivity performance of a solar still for seawater desalination: A review. Desalination, Volume 385, 2 May 2016, Pages 178-193."

[6] "Ahmed, H. M., Hamza, R. M., Ibrahim, G., and Mahmood, Z. M. Temperature Analysis of Conventional Solar Still linked to Passive Cylindrical Condensers. Journal of Advanced Science and Engineering Research Vol 3, No 3 September, 2013, 243-251.”

[7] "Kabeel, E., Omara, Z. M., Essa, F. A., Abdullah, A.S. Solar still with condenser - A detailed review. Renewable, Volume 59, June 2016, Pages 839-857."

[8] "Madhlopa, A. Development of an advanced passive solar still with separate condenser. A thesis submitted in fulfilment of the requirements for the degree of Doctor of Philosophy in Mechanical Engineering, Energy Systems Research Unit Department of Mechanical Engineering, University of Strathclyde, Glasgow, United Kingdom, 2009."

[9] "Madhlopa, A., and Johnstone, C. Numerical study of a passive solar still with separate condenser. Renewable Energy, 2009, 34, (7), pp. 1668 - 1677."

[10] “Ahmed, H. M. Experimental Investigations of Solar Stills Connected to External Passive Condensers. Journal of Advanced Science and Engineering Research, 2012, Vol. 2(1), 1-11."

[11] "Khalifa A-JN, Al-Jubouri A. S. and Abed, M.K.. An experimental study on modified simple solar stills. Energy Convers. Manage. Vol. 40, 1999“, 1835-47."

[12] "Fath, H, and Hosny, H. Thermal performance of a single-sloped basin still with an inherent built-in additional condenser. Desalination, 2002, 142:19-27."

[13] "Ahmed. H. M., Ibrahim, G., Talisic, G. C. Thermal Performance of a Conventional Solar Still with a Built-in Passive Condenser: Experimental studies. Journal of Advanced Science and Engineering Research Vol 7, No 3 September, 2017, 1-12."

[14]"Ibrahim, G., and Ahmed, H. M. Theoretical Modelling for Experimental Study of Solar Still with Integrated Built-in Condenser. ICIRD - the 2018 IEEE International Conference on Innovative Research and Development (ICIRD), Bangkok, Thailand, 11-12 May, 2018. Paper No 65- Published in IEEE Xplorer - Digital Library - 11 June 2018, DOI: 10.1109/ICIRD.2018.8376318. "

15] "Natarajan, K., and Natarajan, A. Factors influencing the performance and productivity of solar stills - A review. Desalination, Volume

$\begin{array}{lc}\text { in } & \text { insulation } \\ \text { pw } & \text { plywood } \\ & \\ \text { r } & \text { radiation } \\ \text { s } & \text { steel (galvanized) } \\ \text { sw } & \text { side } \text { wall } \\ \text { w } & \text { water } \\ \text { w - g } & \text { water-glass" }\end{array}$

\section{REFERENCES}

[1]“Ahmed, H.M., Alshutal, F.S., and Ibrahim, G., Impact of Different Configurations on Solar Still Productivity, Journal of Advanced Science and Engineering Research, 2014, 3, (2), pp. 118-126."

[2] "Bait, O. and $\mathrm{Si}-$ Ameur, O. Enhanced heat and mass transfer in solar stills using nanofluids: A review. Solar Energy, Volume 170, 2018, Pages 694-722."

[3] "Okati, V., Farsad, S., Behzadmehr, A. Numerical analysis of an integrated desalination unit using humidification - dehumidification and subsurface condensation processes. Desalination, Volume 433, 1 May 2018, Pages 172-185."

4] "Omara, Z., Abdullah, A., Kabeel, A., and Essa, F. The cooling techniques of the solar stills' glass covers-A review. Renewable and Sustainable Energy Reviews, 2017, 78, pp. 176-193.

435, 1 June 2018, Pages 181-187."

[16]"Bhardwaj, R., Kortenaar, M. V., and Mudde, R. F. Inflatable plastic solar still with passive condenser for single family use, Desalination 398, 2016, 151-156."

[17]"Dsilva, D., Rufuss, W., Iniyan, S., Suganthi, L., and Davies, P. A Solar stills: A comprehensive review of designs, performance and material advances. Volume 63, September 2016, Pages 464-496."

[18]"Panchal, H. N. Use of thermal energy storage materials for enhancement in distillate output of solar still: A review. Renewable and Sustainable Energy Reviews, Volume 61, 2016, Pages 86-9." 